\title{
SEVERIDADE DA ANTRACNOSE DO FEIJÃO-FAVA AFETADA POR DOSES DE CÁLCIO E FONTES DE SILÍCIO
}

\author{
Antonio Duarte do Nascimento ${ }^{1}$, Frederico Monteiro Feijó ${ }^{1 *}$, Abel Washington de Albuquerque ${ }^{1}$, Iraildes Pereira \\ Assunção $0^{1}$, Gaus Silvestre de Andrade Lima ${ }^{1}$, Lígia Sampaio Reis ${ }^{1}$
}

${ }^{1}$ Centro de Ciências Agrárias, Universidade Federal de Alagoas, BR 104 Norte, Km 85, Rio Largo - AL

*Autor para correspondência: Frederico Monteiro Feijó, frederico.agro2004@gmail.com

\begin{abstract}
RESUMO: A antracnose é uma das mais importantes doenças do feijão-fava, sendo considerada fator limitante no incremento da produtividade da cultura no Nordeste do Brasil. O principal controle utilizado para essa doença é o químico, porém, encarece custos de produção, principalmente, pelo cultivo ser praticado no contexto da agricultura familiar. Desta forma, torna-se fundamental a busca por métodos alternativos para o controle da antracnose na cultura. Diante do exposto, objetivou-se com esse estudo avaliar a influência do silício e do cálcio na severidade da antracnose do feijão-fava. Utilizou-se uma fonte de Cálcio (Carbonato de Cálcio - CaCO3) nas dosagens 2, 4, 6 e $8 \mathrm{~g} \mathrm{~kg}-1$ de solo e duas fontes de Silício (Rocksil e MB4) nas dosagens 0,05, 0,075, 0,1 e $0,15 \mathrm{~g} \mathrm{~kg}-1$ de solo. Em condições de casa de vegetação fez-se o plantio utilizando sementes do genótipo de feijão-fava G35. Aos 30 dias após a germinação, as plantas foram inoculadas com suspensão de esporos de Colletotrichum truncatum na concentração de 106 conídios ml-1. As avaliações da severidade da doença foram realizadas aos 25, 40, 55, 70 e 85 dias após as inoculações, com auxílio de escala diagramática. Os teores de clorofila nas folhas foram avaliados pelo índice SPAD aos 60, 75, 90 e 105 dias após a germinação das sementes. Houve reduções de 66,37\%; 75,34\% e 77,58\% na severidade da doença com o uso de carbonato de cálcio, Rocksil e MB4, respectivamente. Não houve correlação entre as fontes de cálcio e silício testados com 0 conteúdo de clorofila nas plantas avaliadas.
\end{abstract}

PALAVRAS-CHAVE: Phaseolus lunatus, Colletotrichum truncatum, Nutrição mineral.

\section{SEVERITY OF THE LIMA BEAN ANTHRACNOSE AFFECTED FOR DOSES OF CALCIUM AND SILICON SOURCES}

ABSTRACT: Anthracnose is one of the most important diseases of lima bean, being considered limiting factor in increasing culture productivity in Northeast Brazil. The main control used for this disease is the chemical, however, increases production costs, mainly because the cultivation is practiced in the context of the family agriculture. In this way, the search for alternative methods for the control of anthracnose in the culture becomes fundamental. Thus, the aim of this study was to evaluate the influence of silicon and calcium on the severity of the lima bean anthracnose. It was used a source of Calcium (Calcium Carbonate - CaCO3) at dosages 2, 4, 6 and $8 \mathrm{~g} \mathrm{~kg}-1$ of soil and two sources of Silicon (Rocksil and MB4) at the dosages 0.05, $0.075,0.1$ and $0.15 \mathrm{~g} \mathrm{~kg}-1$ soil. Under greenhouse conditions the planting was accomplished using seeds the genotype G35. At 30 days after germination, the plants were inoculated with Colletotrichum truncatum spore suspension at the concentration of $10^{6}$ conidia $\mathrm{ml}^{-1}$. The severity of the disease was evaluated at 25 , $40,55,70$ and 85 days after inoculation, with the aid of a diagrammatic scale. The chlorophyll content in the leaves was evaluated by the SPAD index at $60,75,90$ and 105 days after seed germination. There were reductions of $66.37 \% ; 75.34 \%$ and $77.58 \%$ in disease severity with the use of calcium carbonate, Rocksil and MB4, respectively. There was no correlation between the calcium and silicon sources tested with the chlorophyll content in the evaluated plants.

KEYWORDS: Phaseolus lunatus, Colletotrichum truncatum, fertilizing. 


\section{INTRODUÇÃO}

O feijão-fava (Phaseolus lunatus L.) é uma cultura de relevante importância social e econômica para o nordeste brasileiro, sendo uma das principais fontes de renda e alimento para pequenos agricultores (Cavalcante et al., 2012). Embora bem adaptada às condições edafoclimáticas dessa região, a ocorrência de doenças tem limitado a produtividade da cultura (Silva et al., 2010). Dentre as doenças, a antracnose causada pelo fungo Colletotrichum truncatum, se destaca como uma das mais importantes (Figueiredo, 2001). A doença atinge folhas, ramos e vagens, e quando 0 ataque é mais severo causa redução da produtividade e queda no valor dos grãos comercializados (Lopes et al., 2010).

Para o controle da antracnose, de forma geral, as principais recomendações são o uso de sementes sadias, rotação de cultura e a aplicação de produtos químicos (Wendland et al., 2016), porém 0 uso de fungicidas encarece custos de produção, tornando-se inviável para 0 cultivo de feijão-fava, uma vez que é uma cultura praticada no âmbito da agricultura familiar (Cavalcante et al., 2012). Desta forma, a busca por métodos alternativos para o controle da antracnose nesta cultura torna-se fundamental.

A utilização de elementos como o cálcio e 0 silício vêm sendo bastante estudados por induzirem resistência em plantas a patógenos. Tais elementos são empregados na redução da severidade de muitas doenças, dentre elas, a antracnose (Pozza et al., 2004; Yamada, 2004). 0 cálcio e o silício são absorvidos pelas plantas junto com a água do solo, por fluxo de massa e se deslocam principalmente para os órgãos de transpiração, acumulando-se nas folhas, sendo seus transportes limitados, via floema, para os frutos (Barbosa et al., 2002; Blakenau, 2007). Ambos, ao se acumularem na parece celular, constituem barreiras mecânicas que dificultam ou impedem a penetração de fitopatógenos.

Muitos fungos parasitas e bactérias invadem o tecido vegetal através da produção de enzimas pectolíticas como a poligalacturonase, que dissolve a lamela média. A atividade desta enzima é inibida pelo cálcio (Yamada, 2004). Esse elemento modifica as pectinas hidrossolúveis em polipectato insolúvel, o qual é resistente às enzimas pectolíticas dos patógenos (Zambolim et al., 2001). Já o acumulo de silício na parede celular impede o crescimento e a penetração de microrganismos fitopatogênicos, por ativar os mecanismos naturais de defesa da planta como, produção de compostos fenólicos, quitinases, peroxidases e acúmulo de lignina (Figueiredo e Rodrigues, 2007).

Estudos comprovaram que 0 uso desses elementos pode diminuir a incidência de doenças e ataque de insetos, além de favorecer à fotossíntese por interferir na estrutura das plantas (Ferreira et al., 2009). Características fotossintéticas como as trocas gasosas e os parâmetros da fluorescência da clorofila são consideradas indicadoras eficientes do comportamento do aparato fotossintético quando as plantas são submetidas ao ataque de patógenos (Baker e Rosenqvist, 2004).

Considerando à eficiência destes elementos no controle de doenças de plantas e a importância desses estudos para o manejo sustentável da cultura, o presente trabalho objetivou verificar 0 efeito de diferentes doses de uma fonte de cálcio e duas fontes de silício na severidade da antracnose do feijão-fava.

\section{MATERIAL E MÉTODOS}

Os experimentos foram conduzidos em casa de vegetação no Centro de Ciências Agrárias (CECA) da Universidade Federal de Alagoas (UFAL), localizado no município de Rio Largo, AL. O solo utilizado nos experimentos foi retirado da camada de $0-0,2 \mathrm{~m}$ sendo peneirado numa malha de 2 $\mathrm{mm}$ de abertura e seco ao ar. Uma alíquota do solo foi retirada e enviada para análises de solo, que 0 classificou como Argissolo Amarelo Distrófico típico a moderado, textura Franco-arenoso ( $18 \%$ de argila) (Tabela 1).

Tabela 1. Características químicas do solo utilizado nos experimentos

\begin{tabular}{ccccccccc}
\hline $\mathrm{pH}(\mathrm{H} 2 \mathrm{O})$ & $\mathrm{M} . \mathrm{O}(\%)$ & $\mathrm{P}$ & $\mathrm{H}+\mathrm{Al}$ & $\mathrm{Ca}$ & $\mathrm{Mg}$ & $\mathrm{K}$ & $\mathrm{SB}$ & $\mathrm{CTC}$ \\
\hline & & $\left(\mathrm{mg} \mathrm{dm}^{-1}\right)$ & $\ldots \ldots \ldots \ldots \ldots \ldots \mathrm{Mmol}_{\mathrm{c}} \mathrm{dm}^{-3} \ldots \ldots \ldots \ldots \ldots \ldots \ldots \ldots \ldots \ldots$ & $\%$ & $\%$ \\
\hline 5,6 & 3,65 & 2,8 & 6,6 & 2,9 & 1,5 & 180 & 5,0 & 5,1 \\
\hline
\end{tabular}


Foram conduzidos três experimentos, sendo um para avaliar o efeito do cálcio ( $\mathrm{CaCO} 3)$ e dois para avaliar o efeito do silício (Rocksil e MB4) sobre a severidade da antracnose em folhas de feijão-fava. Ambos os elementos foram testados em um genótipo de feijão-fava (G35) suscetível a antracnose, oriundo do banco de germoplasma do Centro de Ciências Agrárias da UFAL. As sementes foram plantadas em vasos de plástico com capacidade de $11 \mathrm{~L}$. Foram testadas quatro doses de carbonato de cálcio (2, 4,6 e $8 \mathrm{~g} \mathrm{~kg}^{-1}$ de solo), e quatro de Rocksil e MB4 $\left(0,05,0,075,0,1\right.$ e $0,15 \mathrm{~g} \mathrm{~kg}^{-1}$ de solo). 0 tratamento controle foi constituído de solo sem adubação. 0 delineamento experimental utilizado foi inteiramente casualizado (DIC) com seis repetições, sendo cada repetição constituída de uma planta por vaso. As doses de silício foram aplicadas no solo dois dias antes do plantio, enquanto as doses de cálcio foram aplicadas 20 dias antes do plantio. 0 plantio foi realizado de forma direta pela disposição de três sementes de feijão-fava por vaso. Quinze dias após a germinação, as plântulas foram desbastadas deixando-se apenas uma por vaso. Por se tratar de plantas de crescimento indeterminado, foram tutoradas utilizando-se estacas de sabiá de $1,5 \mathrm{~m}$ de altura.

Aos 30 dias após a germinação, as plantas foram inoculadas através da pulverização de uma suspensão de esporos de C. truncatum na concentração de 106 conídios $\mathrm{ml}^{-1}$. $\mathrm{O}$ isolado utilizado no estudo foi o ICT7, obtido no Laboratório de Fitopatologia Molecular - CECA/UFAL, isolado este previamente caracterizado por estudos morfológicos e moleculares (Lima, 2012). Aos 25, 40, 55, 70 e 85 dias após a inoculação a severidade da antracnose nas folhas foi avaliada com o auxílio de uma escala diagramática desenvolvida para feijão comum (Godoy et al., 1997), adaptada para feijão-fava.
Foram também avaliados os teores de clorofila nas folhas com o auxílio do medidor indireto de clorofila Minolta SPAD-502 aos 60, 75, 90 e 105 dias após a germinação das sementes de feijão-fava. Em cada planta tomou-se a média de cinco folíolos dos quais calculouse, posteriormente, a média por tratamento. As médias de severidade das lesões foram submetidas à análise de variância e os valores obtidos comparados pelo teste de Tukey a $5 \%$ de probabilidade e posteriormente a análises de regressão. Adicionalmente, foi avaliado o rendimento de grãos (peso de 100 grãos) para cada experimento e submetidos ao teste de correlação com o grau de severidade da doença. Todas as análises estatísticas foram realizadas no software ASSISTAT 7.7 beta.

O controle de plantas invasoras foi realizado manualmente. Não foi registrada nenhuma ocorrência significativa de pragas. Com vista à manutenção da umidade do solo foi utilizado sistema de irrigação com gotejadores, autocompensantes de vazão 8 $L h^{-1}$, em cada vaso. A duração da irrigação foi de 15 min por dia, assegurando umidade em torno da capacidade de campo.

\section{RESULTADOS E DISCUSSÃO}

No experimento que avaliou o uso de carbonato de cálcio - $\mathrm{CaCO}_{3}$ (calcário) no solo, verificou-se diminuição da severidade da antracnose nas folhas de feijão-fava. Todos os tratamentos diferiram significativamente da testemunha, porém, não houve diferença entre as doses testadas (Tabela 2). A análise de regressão ajustou para a seguinte equação, $y=0,2036 x 2-1,5284 x+3,42$, com coeficiente de determinação de $90,5 \%$ (Figura 1A), onde observouse uma redução de $60,54,66,37,66,37$ e $65,92 \%$ da área foliar lesionada para as doses 1, 2, 3, 4 testadas, respectivamente.

Tabela 2. Efeito de uma fonte de cálcio $\left(\mathrm{CaCO}_{3}\right)$ e de duas fontes de silício (Rocksil e MB4) na severidade da antracnose em folhas de feijão-fava.

\begin{tabular}{lccc}
\hline Tratamentos & $\mathrm{CaCO}_{3}$ & Rocksil & MB4 \\
\hline Testemunha & $2,23 \mathrm{a}^{*}$ & $2,23 \mathrm{a}$ & $2,23 \mathrm{a}$ \\
Dose 1 & $0,88 \mathrm{~b}$ & $0,73 \mathrm{~b}$ & $0,78 \mathrm{~b}$ \\
Dose 2 & $0,75 \mathrm{~b}$ & $0,55 \mathrm{~b}$ & $0,58 \mathrm{~b}$ \\
Dose 3 & $0,75 \mathrm{~b}$ & $0,58 \mathrm{~b}$ & $0,54 \mathrm{~b}$ \\
Dose 4 & $0,76 \mathrm{~b}$ & $0,65 \mathrm{~b}$ & $0,50 \mathrm{~b}$ \\
\hline
\end{tabular}

*Médias seguidas de mesma letra não diferem entre si, de acordo com teste de Tukey a $5 \%$ de probabilidade. 
Figura 1. Relação entre severidade da antracnose em folhas de feijão-fava em função das dosagens de $\mathrm{CaCO}_{3}(\mathrm{~A})$, Rocksil (B) e MB4 (C).

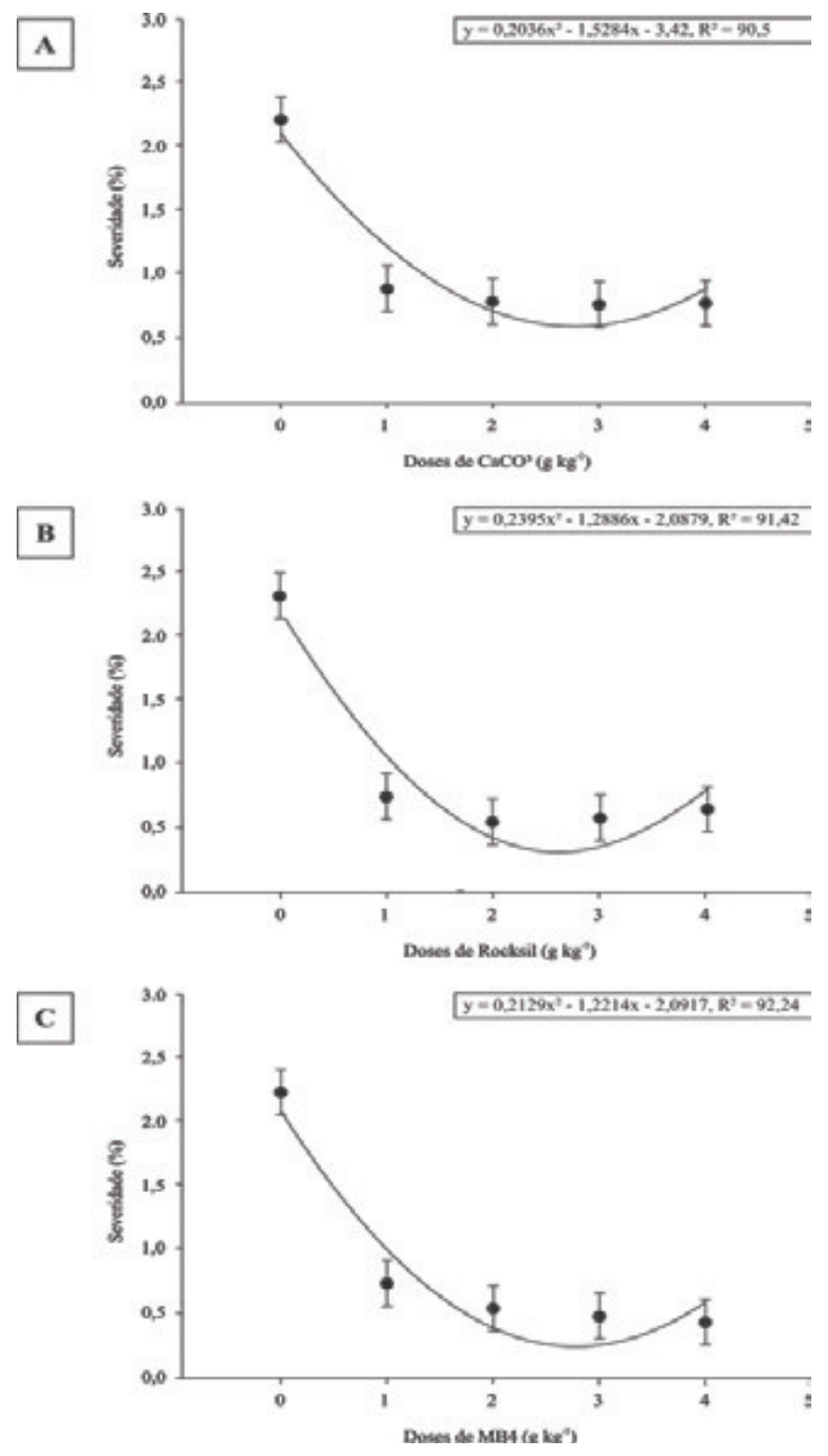

Assim como observado neste estudo, Muniz et al. (1991), avaliando a influência da nutrição com nitrato de cálcio sobre a antracnose do feijão-comum (Phaseolus vulgaris L.) causada por $C$. lindemuthianum, encontraram variações na severidade da doença em função das doses de cálcio, onde observaram maior severidade da antracnose nas plantas tratadas com as menores doses deste elemento. Os autores propõem que o papel do cálcio na redução desta enfermidade esteja relacionado com a absorção de outros nutrientes. Admitem também que o patógeno estudado é bastante variável e que a interação entre outras cultivares de feijão e outras raças do fungo possam resultar em respostas diferentes. Já Muchovej et al. (1980), atribuem a redução da antracnose da soja, causada por $C$. dematium var. truncata, a baixa atividade de enzimas pécticas produzidas pelo patógeno sobre o pectato de cálcio na parede celular. Tal hipótese parece aceitável, pois as poligalacturonases produzidas por esse gênero de fungos podem ser inibidas por cálcio (Yamada, 2004).

Neste estudo a fonte de cálcio utilizada (carbonato de cálcio - $\mathrm{CaCO}_{3}$ ) mostrou-se eficiente no controle da antracnose das folhas de feijão-fava, porém, o uso do cálcio tem demonstrado eficiência também no controle de outras doenças fúngicas, como para a ferrugem da soja causada por Phakopsora pachyrhizi, onde os autores observaram redução em torno de $86 \%$ da severidade da doença com a aplicação de diferentes doses de cálcio combinados com potássio (Pinheiro et al., 2011). Segundo os mesmos autores 0 potássio aumenta a severidade da doença quando as doses de cálcio são baixas. Resultados semelhantes obtidos por Garcia Júnior et al. (2003), observaram redução da incidência da cercosporiose (Cercospora caffeicola) do cafeeiro com a aplicação de cálcio. Os autores perceberam que a incidência da doença decresceu linearmente com 0 aumento das doses de cálcio, obtendo a menor incidência com a maior dose, que inibiu 0 ataque do patógeno em $85,22 \%$. Estes resultados assemelham-se aos encontrados neste trabalho, porém, a maior dose $\left(8 \mathrm{~g} \mathrm{~kg}^{-1}\right.$ de solo) não foi a mais eficiente apesar de não ter diferido estatisticamente das demais doses testadas.

Segundo Zambolim et al. (2001), a aplicação de cálcio tem controlado a murcha do tomateiro, causada por Fusarium oxysporum, em condições experimentais. Os autores informam ainda que muitos fungos fitopatogênicos invadem o tecido vegetal através da produção de enzimas como a poligalacturonase, que dissolvem a lamela média das células. 0 cálcio, além de proporcionar estabilidade à parede celular, possui a capacidade de inibir a ação destas enzimas dificultando assim a entrada de patógenos (Yamada, 2004). Esta informação pode justificar o efeito do $\mathrm{CaCO} 3$ aplicado no solo, sobre a severidade do $\mathrm{C}$. truncatum nas folhas do feijão-fava. $O$ nutriente, rico em cálcio, pode ter inibido a ação das enzimas produzidas pelo patógeno o que dificultou sua penetração e posterior colonização do tecido vegetal.

Nos experimentos que avaliaram duas fontes de silício aplicados no solo, pode-se observar que tanto no experimento utilizando argila silicatada (Rocksil), como para o melhorador de solo (MB4), houve redução significativa da doença em relação à testemunha para todas as doses testadas (Tabela 2). 
Para o experimento com Rocksil, a análise de regressão foi ajustada com a equação: $y=0,2395 \times 2$ $1,2886 x+2,0879$, com coeficiente de determinação de 91,42\% (Figura 1B), demonstrando redução da doença de $67,26,75,34,74$ e 70,8\% para as doses 0,$05 ; 0,075,0,1$ e $0,15 \mathrm{~g} \mathrm{~kg}-1$ de solo, respectivamente. Contudo, não houve diferença estatística entre as doses testadas neste estudo.

Os resultados obtidos neste trabalho corroboram com os resultados de Pratissoli et al. (2007), que observaram menor severidade da varíola do mamoeiro causada Asperisporium caricae, nas folhas de plantas tratadas com Rocksil. A capacidade deste produto em induzir resistência contra fitopatógenos, foi também verificada por Androcioli et al. (2012), que observaram redução de até $71 \%$ na incidência da cercosporiose ( $C$. caffeicola) e $60 \%$ na incidência da ferrugem em folhas de cafeeiro causada por Hemileia vastatrix. Brancaglione et al. (2009), estudando o efeito curativo do Rocksil sobre a severidade de Xanthomonas axonopodis pv. passiflorae em mudas de maracujazeiro-amarelo, também encontraram resultados satisfatórios. Todas as doses testadas proporcionaram significativo controle em relação à testemunha, entretanto não diferiram significativamente entre si, corroborando com os resultados obtidos neste estudo. Os autores, ainda ressaltam que, além do efeito direto sobre fitopatógenos, a argila silicatada pode aumentar 0 grau de resistência das plantas às injúrias mecânicas (ferimentos) na epiderme, vias que podem facilitar a penetração de patógenos no hospedeiro.

Para o experimento utilizando o MB4, o gráfico com a equação: $y=0,2129 \times 2-1,2214 x+2,0917$ e 0 coeficiente de determinação de 92,24\% (Figura 1C), possibilitou observar redução significativa na severidade da doença em relação ao tratamento controle. As doses testadas não diferiram significativamente entre sí, apresentando percentual de controle de $65,74,75,8$ e 77,58\% paras as doses 1, 2,3 e 4, respectivamente. Verificou-se também que quanto maior a dosagem de MB4, maior foi o percentual de controle da antracnose do feijão-fava, ou seja, menor área foliar lesionada.

0 uso de silício nas culturas vem sendo bastante estudado (Pozza et al., 2004; Fernandes et al., 2009; Moraes et al., 2009; Albuquerque et al., 2013). Teixeira et al. (2008) observaram redução significativa da antracnose (C. lindemuthianum), mancha angular (Pseudocercospora griseola) e crestamento bacteriano (Xanthomonas axonopodis pv. phaseoli) em folhas de feijão-comum utilizando o silício como indutor de resistência. Os resultados estão de acordo com 0 trabalho de Moraes et al. (2006) que encontraram redução em torno de $56 \%$ na severidade da antracnose em folhas de feijoeiro ( $C$. lindemuthianum) utilizando 0 silicato de sódio como fonte de silício.

Assim como observado neste estudo, a capacidade do silício em atenuar o ataque de patógenos de plantas foi observada por vários autores (Pozza et al., 2003; Moraes et al., 2006; Costa et al., 2007; Reis et al., 2008). Segundo Fernandes et al. (2009), várias doenças causadas por fungos e bactérias em diversas culturas podem ser reduzidas significativamente com a fertilização silicatada. Com a presença do silício na parede celular, ocorre a formação uma camada rígida que impede ou dificulta 0 acúmulo e a penetração dos microrganismos (Cogo et al., 2011). Assim, o elemento tem como função a proteção mecânica dos tecidos vegetais onde há grande penetração de patógenos (Fernandes et al., 2009), o que justifica a redução da severidade da antracnose nas folhas tratadas com Rocksil e com MB4.

Em relação ao teor de clorofila presente nas folhas de feijão-fava, não houve aumento no teor de clorofila nas folhas independentemente das doses ou produtos utilizados (Figura 2). Estes resultados corroboram com os resultados obtidos por Pinheiro et al. (2011), demonstrando não haver aumento no teor de clorofila nas folhas em função das doses de cálcio testadas para ferrugem da soja (Phakopsora pachyrhizi). No caso do silício não existem estudos que comprovem o aumento do teor de clorofila em função de sua presença nas células. Segundo Korndörfer e Datnoff, (1995), o silício influência na taxa fotossintética por favorecer a arquitetura foliar, não havendo assim correlação com seu acúmulo nos tecidos da planta.

Figura 2. Índice SPAD (Teor de clorofila) nas folhas de feijão-fava em função das doses de $\mathrm{CaCO}_{3}$, Rocksil e MB4.

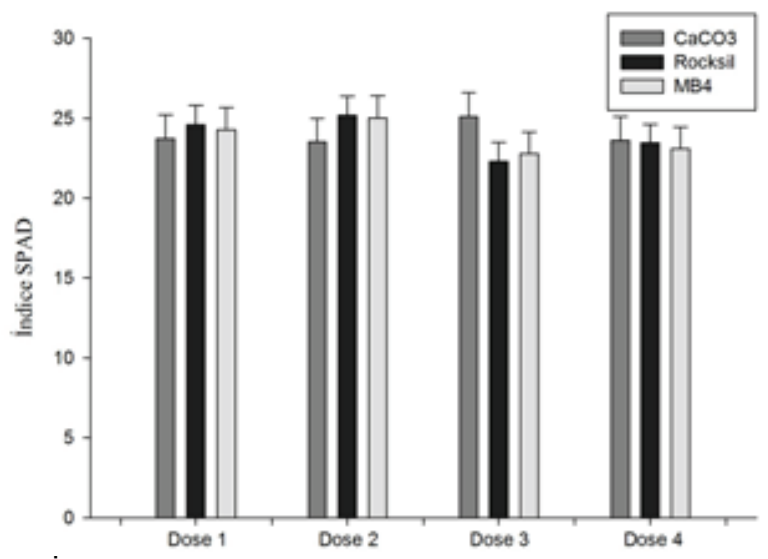


silício utilizadas neste estudo, ou seja, a medida que a severidade da doença aumentou, o peso de 100 grãos de feijão-fava foi reduzido, contudo, não houve diferença significativa entre os coeficientes de correlação obtidos (Tabela 3). Teixeira et al. (2008), atribuem o maior rendimento de grãos de feijãocomum obtidos no período seco, a menor incidência de doenças, dentre elas à antracnose. Porém, os próprios autores admitem a carência de estudos que comprovem esta relação. Os resultados obtidos para as correlações entre produtividade e severidade de antracnose nesse estudo, foram pouco conclusivos, sendo necessárias novas pesquisas para tentar estabelecer precisamente essa relação.

Tabela 3. Coeficiente de correlação ( $r$ ) entre severidade da antracnose e o peso de 100 grãos de feijão-fava nas diferentes fontes testadas.

\begin{tabular}{ccc}
\hline Fonte & $\mathrm{R}$ & Significância \\
\hline $\mathrm{CaCO}_{3}$ & $-0,185$ & $\mathrm{~ns}^{*}$ \\
Rocksil & $-0,705$ & $\mathrm{~ns}$ \\
$\mathrm{MB} 4$ & $-0,604$ & $\mathrm{~ns}$ \\
\hline
\end{tabular}

${ }^{*}$ ns - não significativo a 5\% de probabilidade

Os resultados obtidos demonstraram a eficiência da aplicação tanto da fonte de cálcio quanto para as duas fontes de silício utilizadas nesse estudo, comprovada pela redução significativa da severidade da antracnose das folhas de feijão-fava, quando comparados com o tratamento controle. Desta forma, é possível concluir que a aplicação de cálcio (CaCO3) e silício (Rocksil e MB4) aplicados no solo promove redução na severidade da antracnose em folhas de feijão-fava. Não houve correlação entre as fontes de cálcio e silício testados neste estudo com 0 conteúdo de clorofila nas plantas avaliadas.

\section{AGRADECIMENTOS}

Ao Conselho Nacional de Desenvolvimento Científico e Tecnológico (CNPq), Fundação de Amparo à Pesquisa do Estado de Alagoas (FAPEAL), Coordenação de Aperfeiçoamento de Pessoal de Nível Superior (CAPES) pelo apoio financeiro e ao Centro de Ciências Agrárias da Universidade Federal de Alagoas (CECA/UFAL), pelo espaço disponibilizado.

\section{REFERÊNCIAS BIBLIOGRÁFICAS}

Albuquerque, A.W.; Santos, J.M.; Farias, A.P. Produtividade e qualidade pós-colheita de helicônia Golden torch submetida a fontes e doses de silício. Revista Brasileira de Engenharia Agrícola e Ambiental, 2014, 18, 2, 173-179.

Androcioli, H.G.; Júnor, A.O.M.; Hoshino, A.T.; Androcioli, L.G. Produtos alternativos no controle da Hemileia vastatrix (Berkeley \& Broome) e Cercospora coffeicola (Berkeley \& Cooke) em cafeeiros. Coffee Science, 2012, 7, 2, 187-197.

Baker, N.R.; Rosenqvist, E. Applications of chlorophyll fluorescence can improve crop production strategies: an examination of future possibilities. Journal of experimental botany, 2004, 55, 403, 1607-1621.

Barbosa Filho, M.P.; Prabhu, A.S. Aplicação de silicato de cálcio na cultura do arroz. Embrapa Acre-Circular Técnica (INFOTECA-E), 2002.

Berger, S.; Sinha, A.K.; Roitsch, T. Plant physiology meets phytopathology: plant primary metabolism and plant-pathogen interactions. Journal of experimental botany, 2007, 58, 15-16, 4019-4026.

Blankenau, K. cálcio no solo e na planta. In: Informações Agronômicas, 2007, 117, 17-19.

Brancaglione, P.; Sampaio, A.C.; Fischer, I.H.; Almeida, A.M.; Fumis, T.F. Eficiência de argila silicatada no controle de Xanthomonas axonopodis pv. passiflorae, in vitro e em mudas de maracujazeiro-amarelo. Revista Brasileira de Fruticultura, 2009, 31, 718-724.

Cavalcante, G.R.S.; Carvalho, E.M.S.; Gomes, R.L.F.; Santos, A.R.B.; Santos, C.M.P.M. Reação de subamostras de feijão-fava à antracnose. Summa Phytopathologica, 2012, 38, 4, 329-333.

Cogo, F.D.; Graciano, G. S.; Campos, K.A. Ação do silicato de cálcio e magnésio na redução de Cercospora coffeicola. Engenharia Ambiental, 2011, 8, 2, 116-126.

Costa, M. J. N.; Zambolim, L.; Rodrigues, F. A. Avaliação de produtos alternativos no controle da ferrugem do cafeeiro. Fitopatologia Brasileira, 2007, 32, 2, 150-155. 
Fernandes, A.L.T.; Merrighi, A.L.N.; Silva, G.A.; Fraga Júnior, E.F.F. Utilização do silício no controle de pragas e doenças do cafeeiro irrigado. Revista Uberaba, 2009, $4,6,11-52$.

Ferreira, R.L.F.; Souza, R.J.; Carvalho, J.G.; Araújo Neto, S.E.; Yuri, J.E. Avaliação de cultivares de alface adubadas com Silifértil@. Caatinga, 2009, 22,.2, 5-10.

Figueiredo, F. C.; Rodrigues, C. R. Silício líquido solúvel: a sinergia entre a nutrição e defesa de plantas. Revista Campo \& Negócio, 2007, 15, 47,.12.

Figueiredo, M.B. Doenças fúngicas emergentes em grandes culturas. O Biológico, 2001, 63, 29-32.

Godoy, C.V.; Carneiro, S.M..; lamauti, M.T.; Pria, M.D.; Amorim, L.; Berger, R.D.; Bergamin Filho, A. Diagrammatic scales for bean diseases: development and validation/Diagrammatische Boniturskalen für Bohnenkrankheiten: Entwicklung und Validation. Zeitschrift für Pflanzenkrankheiten und Pflanzenschutz/Journal of Plant Diseases and Protection, 1997, 104, 4, 336-345.

Júnior, D.G.; Pozza, E.A.; Pozza, A.A.; Souza, P.E.; Carvalho, J.G.; Balieiro, A.C. Incidência e severidade da cercosporiose do cafeeiro em função do suprimento de potássio e cálcio em solução nutritiva. Fitopatologia Brasileira, 2003, 28, 3, 286-291.

Korndörfer, G.H.; Datnoff, L.E. Adubação com silício: uma alternativa no controle de doenças da cana de açúcar e do arroz. Informações Agronômicas, 1995, 70, 1-3.

Lima, J. F. Caracterização Morfocultural e Molecular de Isolados de Colletotrichum Agente Causal da Antracnose do Feijão-fava no Estado de Alagoas. 2012. 52 f. Dissertação (Mestrado em Agronomia) Universidade Federal de Alagoas, Alagoas.

Lopes, A. C. A.; Gomes, R. L. F.; Araújo, A. S. F. A cultura do feijão-fava no Meio-Norte do Brasil. p. 191203, EDUFPI, 2010.

Moraes, S.R.; Pozza, E.A.; Alves, E; Pozza, A.A.; Carvalho, J.G.; Lima, P.H.; Botelho, A.O. Efeito de fontes de silício na incidência e na severidade da antracnose do feijoeiro. Fitopatologia Brasileira, 2006, 31, 1, 69-75.

Moraes, S.R.G.; Pozza, E.A.; Pozza, A.A.A.; Carvalho, J.G.; Souza, P.E. Nutrição do feijoeiro e intensidade da antracnose em função da aplicação de silício e cobre. Acta Scientiarum. Agronomy, 2009, 31, 2, 283-291.

Muchovej, J.J.; Muchovej, R.M.C.; Dhingra, O.D.; Maffia, L.A. Suppression of anthracnose of soybeans by calcium. Plant disease, 1980, 64,12, 1088-1089.

Muniz, M.F.S.; Muchovej, J.J.; Muchovej, R.M.C.; Venegas, V.H.A.; Brommonschenkel, S.H.; Maffia L.A. Influência da nutrição com cálcio sobre a antracnose em feijão. Pesquisa Agropecuária Brasileira, 1991, 26, 11-12, 2025-2031.

Pinheiro, J.B.; Pozza, E. A.; Pozza, A. A. A.; Moreira, A. D. S.; Alves, M. C. Severidade da ferrugem da soja em função do suprimento de potássio e cálcio em solução nutritiva. Revista Ceres, 2011, 58, 1, 43-50.

Pozza, A.A.; Alves, E.; Pozza, E. A.; Carvalho, J. D.; Montanari, M.; Guimarães, P. T.; Santos, D. M. Efeito do silício no controle da cercosporiose em três variedades de cafeeiro. Fitopatologia Brasileira, 2004, 29, 185-188.

Pratissoli, D.; Dias De Almeida, G.; Júnior, J.; Cintra, W.; Vicentini, V.B.; Mathias Holtz, A.; Goronci Cocheto, J. Fertilizante organomineral e argila silicatada como indutores de resistência à varíola do mamoeiro. Idesia, 2007, 25, 2, 63-67.

Reis, T. H. P. et al. Efeito da associação silício líquido solúvel com fungicida no controle fitossanitário do cafeeiro. Coffee Science, 2008, 3, 1, 76-80.

Silva, J. A.; Oliveira, M. G.; Souza, L. T.; Michereff, S. J.; Assunção, I. P.; Andrade Lima, G. S. Reação de genótipos de fava (Phaseolus lunatus L.) à podridão do colo causada por Sclerotium rolfsii, Recife, PE, 2010. In.: X Jornada de ensino, pesquisa e extensão - jepex 2010 - UFRPE Recife, PE. Disponível em:<http:// www.sigeventos.com.br/jepex/inscricao/resumos/0001/ R0679 1.PDF>.Acesso em: 19 jan. 2011.

Teixeira, I. R.; Silva, R. P.; Silva, A. G.; Korndörfer, P. H. Fontes de silício em cultivares de feijão nas safras das 
águas e da seca. Revista Ciência Agronômica, 2008, Zambolim, L.; Costa, H.; Vale, F. X. R.; Zambolim, L. $39,4,562-568$.

Efeito da nutrição mineral sobre doenças de plantas causadas por patógenos do solo. Manejo integrado,

Wendland, A.; Moreira, A.S.; Bianchini, A.; Giampan, $\quad$ fitossanidade, cultivo protegido, pivô central e plantio J.S.; Lobo Jr., M. Doenças do feijoeiro. In: Amorim, L. direto. Suprema Gráfica e Editora Ltda, p. 347-408, et al. Manual de Fitopatologia, v.2, ed.5, p.383-396. 2001.

Editora Ceres, 2016.

Yamada, T. Resistência de plantas às pragas e doenças: pode ser afetada pelo manejo da cultura? Informações Agronômicas, 2004, 1, 108, 1-7. 